\title{
FLUID SATURATIONS FROM ELECTRICAL MEASUREMENTS BETWEEN WELLS
}

by

Dexter Sutterfield and Erle C. Donaldson
- NOTICE -

This report was prepared as an arcount of work sponsored by the United States Governinent. Neither the United States not the United State:s Department of Energy, nor any of their employees, nor any of their contractors, subcontractors, or their tmployees, makes any warranty, express or implied, or assumes any lega! liability or responsibility for the accurscy, completeness or usefulness of any information, appiratus, product or process disclosed, or represents that its use would not infringe privately owned rights.

\section{Bartlesville Energy Technology Center} Bartlesville, Oklahoma

Date Published-February 1979

U.S. Department of Energy TECHNICAL INFORMATION CENTER

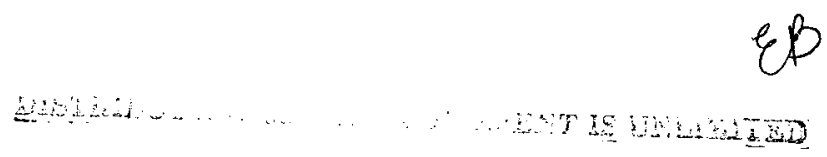




\section{DISCLAIMER}

This report was prepared as an account of work sponsored by an agency of the United States Government. Neither the United States Government nor any agency Thereof, nor any of their employees, makes any warranty, express or implied, or assumes any legal liability or responsibility for the accuracy, completeness, or usefulness of any information, apparatus, product, or process disclosed, or represents that its use would not infringe privately owned rights. Reference herein to any specific commercial product, process, or service by trade name, trademark, manufacturer, or otherwise does not necessarily constitute or imply its endorsement, recommendation, or favoring by the United States Government or any agency thereof. The views and opinions of authors expressed herein do not necessarily state or reflect those of the United States Government or any agency thereof. 


\section{DISCLAIMER}

Portions of this document may be illegible in electronic image products. Images are produced from the best available original document. 


\section{CONTENTS}

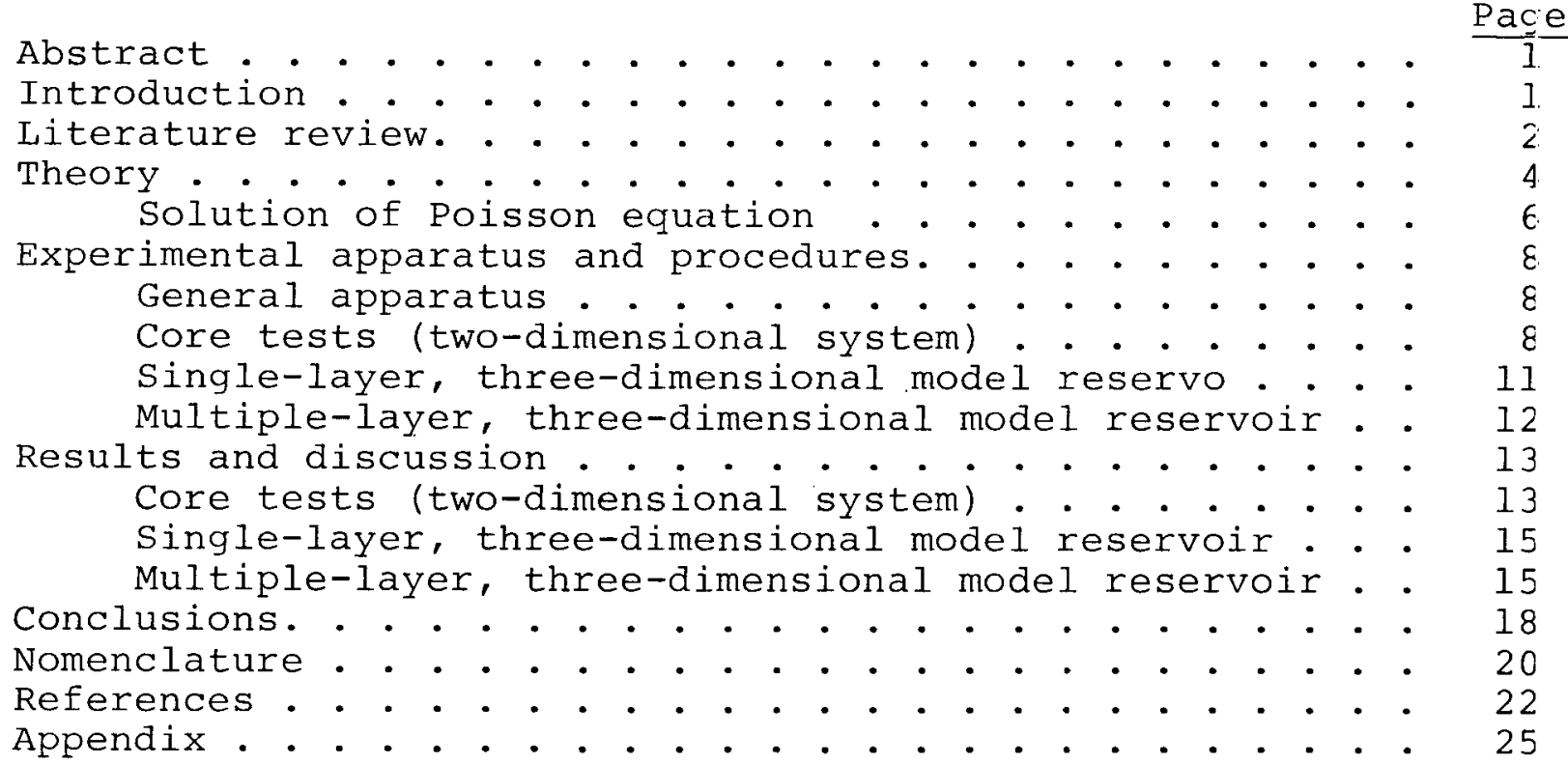

\section{ILLUSTRATIONS}

$\frac{\text { Fig. }}{1}$

Method used to measure the resistivity across an oilfield. The chemical reactions of oxidation and reduction are shown at each well. . . . . . . . . .

2. Signal input and measurement for ac or dc measurements of the core or the model reservoir. Numbered circles indicate electrodes. . . . . . . . . . . . . 9

3. Method used to determine the resistivity of a core . . 9

4. Resistivity as a function of brine saturation determined using a 76-cm-long by $3.8-\mathrm{cm}$-diameter core . . 14

5. Brine saturation distribution calculated from the Poisson equation for a single-layer, three-dimensional model reservoir. . . . . . . . . . . . . 17

6. Isopotential lines calculated from the solution of Poisson's equation with input at wells $\mathrm{W}-1$ and $\mathrm{W}-2$ in a single layer-model. . . . . . . . . . . . .

7. Brine saturation distribution calculated between wells in a multilayered three-dimensional model reservoir using Poisson's equation . . . . . . . . . . . 18

A-1 Finite difference grid. . . . . . . . . . . . . 26

A-2 Relationship between the known (filled-in circles) and unknown (open circles) values in the gird.. . 27 


\section{ILLUSTRATIONS-Continued}

$\frac{\text { Fig. }}{A-3}$ Computer Program for calculation of voltages and water saturation in a laboratory model . . . . 29-33

A-4 Flow diagram of the computer program showing the main characteristics.

TABLES

1. Results of resistivity measurements using oxidizing and reducing solutions. . . . . . . . . . . . . .

2. Water saturation between electrodes in the single layer three-dimensional model reservoir calculated by the finite difference solution of Poisson's equation. . . . . . . . . . . . . . . . . . 


\title{
FLUID SATURATIONS FROM ELECTRICAL MEASUREMENTS BETWEEN WELLS
}

by

Dexter SutterfieldI/ and Erle C. Donaldson 2/

\begin{abstract}
The feasibility of using electrical communication between wells to determine the average interwell fluid saturation was tested with a long core and three-dimensional model reservoirs. Two methods were proposed. The first employed an oxidizing solution in one well and a reducing solution in another to obtain an electric current through the reservoir from chemical reaction; the second, an impressed current between the wells and measurement of the potential difference. Experimental determination of the overall brine saturation using the electrical fields agreed with the volumetric amounts of brine and oil with which the model reservoirs were saturated. General mapping of the saturation distribution of the three-dimensional reservoir was also possible using a finite difference solution of Poisson's equation.
\end{abstract}

\section{INTRODUCTION}

The declining production of domestic oil has placed considerable emphasis on the development of new technology for production of residual oil remaining after the economic limit of oil production by primary and secondary methods has been reached. Research for the development of new technology for tertiary oil production has emphasized the importance of accurately determining the oil saturation and its distribution in an oilfield. Three principal methods currently are used for estimating fluid saturations in oilfields: (1) core analysis: extraction of cores followed by laboratory analysis of oil reservoir rock samples, (2) logging: interpretation of electrical, acoustical, and radioactive signals obtained from specialized tools lowered into the wells, and (3) material balance calculations: estimation of remaining fluid content by subtracting the produced fluid volumes from the initial estimates of the reservoir saturations. Each of these methods has varying degrees of accuracy depending upon laboratory and sampling techniques. Core analysis yields the fluid saturation of a small sample which generally is con-

\footnotetext{
If Research Chemist

2/ Project Leader
} 
taminated with fluids used in drilling. Logging produces measurements of fluid saturation but only within a few feet from the wellbore and those measurements may yield grossly inaccurate estimates of the formation saturation if water coning has occurred at the well. Material balance calculations depend upon the accuracy of (1) initial oil saturation estimates, (2) production records that may be 25 to 40 years old, and (3) calculated estimates of pressure decline in the reservoir. None of these methods yield information about the interwell saturation distribution unless new wells are drilled throughout the field.

The ultra-long-spaced electric logs (ULSEL) employ spacing between the electrodes ranging from 30 to 300 meters (25) 3 . Information from the ULSEL and induction log readings are used to determine the profile of salt domes or cased wells in the vicinity by mapping the resistivity contrast between the salt or well casing and the other formations. Surface resistivity profiles of the earth, using long electrode spacings, are also used in prospecting for ores.

Mineral prospecting is conducted by measuring the natural earth currents produced by the galvanic action of the minerals and by measuring the isopotential lines developed from a current which is impressed directly into the ground. The mathematical interpretation of the pattern of current flow from the electrodes is based upon the Laplace equation (27).

This work was initiated to test the feasibility of using electric measurements between wells to obtain the average resistivity and from this the average fluid saturation between the wells. The two methods discussed in this report are similar to the two prospecting methods. In the first case, a potential is developed by introducing an oxidizing solution at one point and a reducing solution at another to develop an electric potential in a manner similar to the operation of a battery. In the second case, a current is impressed into the oil reservoir and the potential is measured to obtain the average resistivity between the electrodes.

\section{LITERATURE REVIEW}

Dry sandstones, unconsolidated sands, carbonate rocks, oil, and gas have such high resistances to an electric current that they are considered as insulators. Minerals, especially clay and pyrite, frequently associated with the sedimentary rocks that make up most petroleum reservoirs are conductive and, consequently, complicate the interpretation of resistivity logs. However, if

3/ Underlined numbers in parentheses refer to the list of references at the end of the paper. 
we assume that the porous rock matrix is nonconductive, the electrical properties depend only upon the brine contained in the pores of the rock and the geometry of the pores. Then the con-ductivity of a fluid-saturated rock is due to the ions of the dissolved salts that make up the brine. Consequently, the magnitude of the electrical conductivity depends upon the salt concentration and temperature.

The resistivity of a material is the reciprocal of the conductivity and is defined as

$$
\rho=\frac{r \cdot A}{L}
$$

The value of the resistivity of a rock which is completely saturated with brine of a given concentration at a specific temperature is important for interpreting resistivity data. This value is the formation resistivity factor and was defined by Archie (ㅁ) as follows:

$$
\mathrm{F}=\frac{\mathrm{R}_{0}}{\mathrm{R}_{\mathrm{w}}}
$$

As an aid to interpretation of electric logs, Rall and Wright (24) published the mineral analysis and resistivity of 600 oilfield brines measured at $60^{\circ}, 80^{\circ}, 100^{\circ}$, and $120^{\circ} \mathrm{F}$, and Arps (4) made a comprehensive study of the effect of temperature on the density and resistivity of sodium chloride solutions.

Guyod (11) noted that the formation factor increases as the sand becomes more cemented and established the dependence of the exponent, $\mathrm{m}$, on the degree of cementation of the sand.

Archie gives an empirical relationship for water saturation. For clean, water-saturated sands the average value of $n$ is 2; hence, the water saturation may be estimated with a fair degree of accuracy using the empirical relationship:

$$
S_{W}=\left(R_{0} / R_{t}\right)^{1 / n}=\left(F_{w} / R_{t}\right)^{0.5}
$$

The process of obtaining accurate data becomes increasingly difficult when the sedimentary formation being measured contains variable amounts of shale and silty materials. Early tests conducted by Patnode and Wyllie (22) developed conclusive data showing that wet rocks containing clay and other minerals have appreciable conductivity.: The total measured conductivity was equal to the sum of the conductivity of the rock and brine. Perkins, Jr. and others (23) extended the work of Patnode and Wyllie by studying the abnormal resistivity associated with the 
presence of shaly materials in sedimentary formations. They concluded that the abnormal electrical characteristics are due to the adsorption of ions from the brines by the shaly materials and derived a mathematical interpretation based on their laboratory results that verified their conclusions. Later, Wyllie and Southwick (36) reported on an experimental investigation of the effects of ion exchange materials on the electrical conductivity of porous media.

Van Nostrand and Cook (27) presented a comprehensive review of the interpretation of electrical resistivity data when applied to prospecting for minerals and survey of subsurface heterogeneities. They note that direct-current methods of prospecting are based on measurements of isopotential contours resulting from a direct current impressed into the ground. The theory is predicted by the Laplace equation for obtaining the electrical potential and pattern of flow of the current from the ground electrodes. The only differences between methods of directcurrent prospecting are the spacing of electrodes, the electrical parameters determined, and the magnitude of the impressed current. Anomalies in resistivity are interpreted to define and quantify ore bodies; and interruptions of the isopotential lines are indicative of faults and other geologic heterogeneities. Since electrode spacing of 100 meters can be used and large areas can be examined, it seems feasible to apply this technique in determining the apparent resistivity between wells in an oilfield. If this can be done by focusing a current through an oil zone and then measuring the apparent resistivity between adjacent wells, some estimate of the saturation distribution of brine in the formation can be obtained. The saturation between wells and its distribution throughout an oilfield is vital to the initiation of an enhanced oil recovery program for any field.

\section{THEORY}

The theory of electric logging to determine fluid saturations is wel1 documented $(3,13,16,18,30,35)$. Equation (3) is used to determine the water saturation of porous media in the absence of clay.

The resistivity, $R_{0}$, of the rock when 100 percent saturated with brine is determined by one of two possible methods. Dunlap and others (8) describe a laboratory method using core samples from the oil reservoir. The hydrocarbons are removed from the formation rock samples by pumping acetone through the core. The salts are then removed by pumping water through the same core. The core sample is saturated with formation brine which is obtained from the production of a well in the formation. Resistivity measurements are made, and $R_{0}$ is determined. 
The second method for obtaining $R_{0}$ is a logging method described by Fertl and Reynolds (9). Formation brine is pumped from the well and stored. An oil-miscible solution is injected into the bore hole in sufficient quantity to displace the oil in the formation surrounding the bore hole. The formation brine that was produced earlier is injected into the bore hole displacing the oil-miscible solution away from the bore hole. Logging measurements are made with the formation 100 percent saturated with brine, and $R_{0}$ is determined.

To determine the apparent resistivity, $R_{t}$, between wells, a current must pass through the formation. By use of Archie's equation, the saturation distribution of brine throughout the field can then be mapped. An electric potential may be developed between wells using dc or ac emf impressed between electrodes in the wells or by forming an in situ battery by injecting a reduaing solution (one capable of being oxidized), such as $\mathrm{FeCl}_{2}$, into one well and an oxidizing solution (one capable of being reduced), such as FeCl, into another well within the same oil-producing formation (flgure 1).

When an oxidizing solution is introduced in one well and a reducing solution into another well and the two wells are connected by means of an electric conductor at the surface, an electric current will flow between wells in the same manner as the operation of a storage battery (28). The electric current flows from the oxidizing solution to the reducing fluid through the brine and back through the conducting wire on the surface. The chemically induced electric current traveling through the interstitial fluids is used to measure the electrical resistivity of the formation, $\mathrm{R}$, which is directly related to the fluid saturation using established correlations $(3,6,8,14,16,18,21$, $30-33,35)$.

The process of causing dc or ac current to flow through a formation consists of impressing a voltage at one electrode and completing the electrical circuit at another electrode in the same formation.

For two-dimensional systems with one-dimensional paths (cores), $\mathrm{R}_{t}$ is calculated directly by the simple relationship:

$$
R_{t}=\varnothing E_{t} A /\left(I_{t} \sqrt{2} L\right)
$$

However, the two-dimensional path in the three-dimensional system is much more complicated. In this research a finite difference solution of the Poisson equation for calculating $R_{t}$ was developed. 


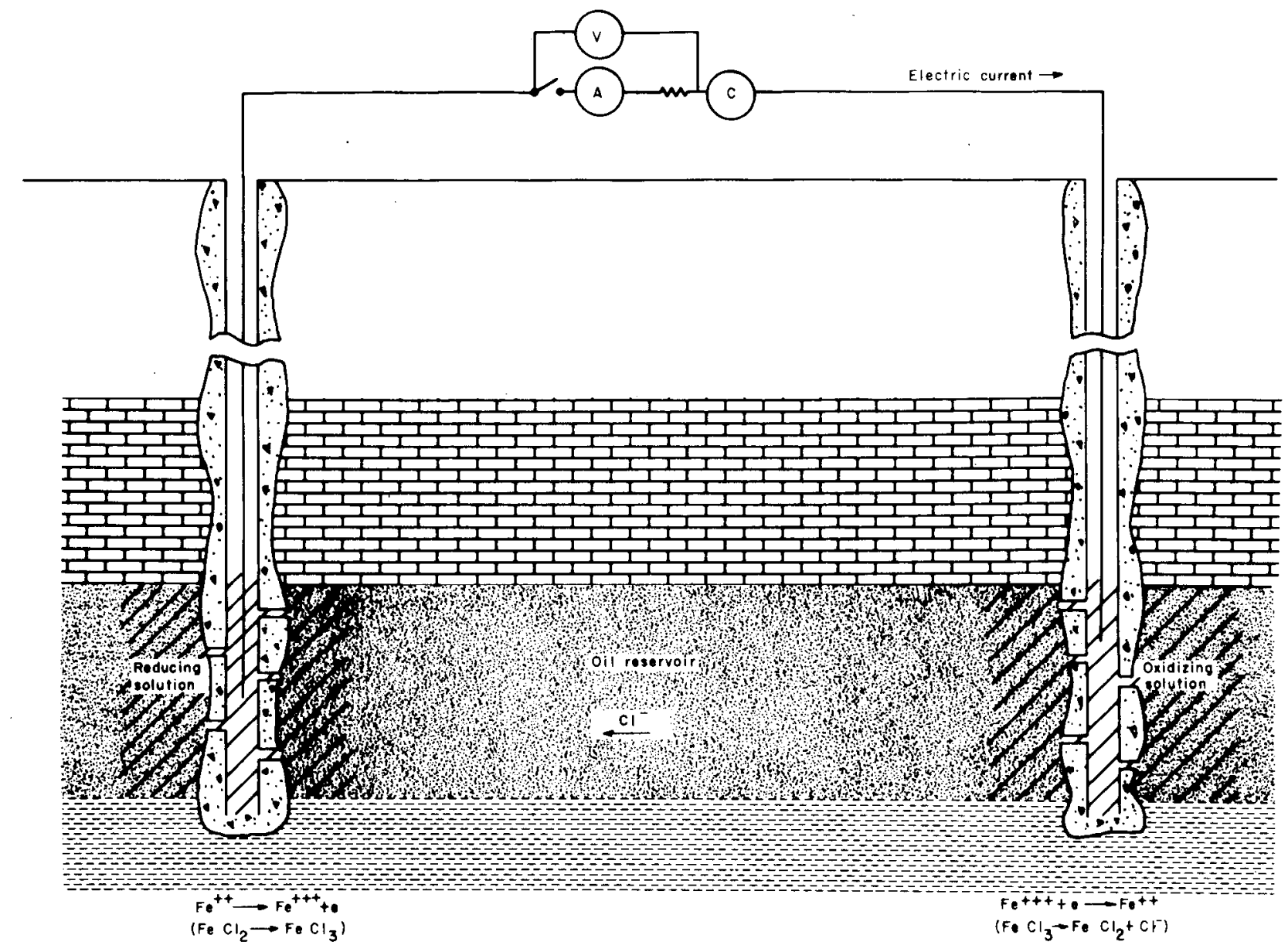

FIGURE 1. - Method used to measure the resistivity across an oilfield. The chemical reactions of oxidation and reduction are shown at each well.

Solution of the Poisson Equation

The apparent resistivity distribution between wells in a three-dimensional model of finite lateral extent was calculated by first assuming that the conductive medium between the measuring electrodes consists of a homogeneous, isotropic layer of constant thickness. In actual practice, this is undoubtedly an oversimplification of the system; however, provisions are made for computations with estimated variations of thickness. Obviously, this yields an estimation of resistivity variation in two horizontal dimensions which is used to determine the brine saturation distribution between wells in the field.

The behavior of an electric current in a nonuniform medium is governed by Poisson's equation: 


$$
\begin{aligned}
& -\nabla \cdot\left[\frac{1}{\rho(x, y, z)} \cdot \nabla \cdot V(x, y, z)\right]=\frac{\partial Q(x, y, z)}{\partial t}= \\
& q(x, y, z)
\end{aligned}
$$

Using the assumptions introduced above, equation (5) is restricted to: (a) two independent variables ( $x$ and $y$ ) representing the surface, (b) an effective thickness, $\varnothing Z_{i j}$, which is specified at each node of the finite difference grid, and (c) an apparent homogeneous medium in which $\rho$ is a constant value between. a pair of measuring electrodes. This reduces equation (5) to a more manageable form:

$$
-\left[\frac{\partial}{\partial x}\left(z_{i, j} \frac{\partial v}{\partial x}\right)+\frac{\partial}{\partial y}\left(z_{i, j} \frac{\partial v}{\partial y}\right)\right]-\rho q(x, y) / \emptyset=0
$$

The current supplied to the ground, by means of the electrodes, is expressed in amperes; whereas, the current density, $q$, represents the rate of charge generation (or adsorption) per unit area normal to the path of current flow. Therefore, it is desirable to express $q$ in terms of current flowing into the ground. When the current is supplied to a two-dimensional system, the current density at the electrode is represented by $I / A$ where $A$ is the area of the outer surface of the electrode and, therefore, the term $\left(\rho q_{(x, y)}\right)$ of equation $(6)$ becomes:

$$
\rho q_{(x, y)} / \varnothing=\rho I / A \varnothing
$$

Dirichlet boundary conditions ( $V_{i} j=0$ at all boundaries) were used rather than von Neuman conditions because they are simpler and will yield an underestimation of potentials rather than an overestimation which is associated with the von Neuman boundary conditions: Furthermore, this model is designed to represent a small laboratory model having perfectly insulated boundaries far removed from the source and sink electrodes.

The influence of image electrodes, as described in detail by van Nostrand (27), was used. The finite difference grid was expanded and image electrodes identical to the original source and sink in magnitude and sign are included outside the actual boundary at a distance equal to the distance from the boundary to the actual electrode. This solution, including the computer program, is shown in detail in the appendix. 


\title{
EXPERIMENTAL APPARATUS AND PROCEDURES
}

\author{
General Apparatus
}

Two multimeters were used for the current and voltage measurements: a Fluke Model 8600 a digital multimeter with both ac and dc capability and a Keithley Model l60B digital multimeter.

Figure 2 shows the schematic for both ac and dc measurements for either the core or the three-dimensional reservoir. This is essentially Rust's (26) configuration for two- and four-electrode resistivity measurements. For ac measurements, a Hewlett Packard Model $200 \mathrm{~B}$ ac generator with a frequency range of $20 \mathrm{~Hz}$ to $20 \mathrm{KHz}$ and 0 to $20 \mathrm{v}$ output was used as the signal generator. A Hewlett Packard Model 2llA generator was used to generate square wave dc. The frequency range of the $211 \mathrm{~A}$ is $1 \mathrm{~Hz}$ to 1 megaHz with 0 to 20 $v$ output.

The current in the circuit was determined by measuring the voltage drop across a precision resistor (figure 2) with the voltmeter switch in position one. Input electrodes 1 and 2 can also be used as measuring electrodes when switch 2 is in position 2 (two-electrode method). The four-electrode measurement occurs when input is to electrodes 1 and 2 and measurements are taken at electrodes 3 and 4 (switch 2 in position 1 ). In the threedimensional model, the 4-electrode measurements were unsatisfactory, and a 2- and 3-electrode method was used by having one side of switch 2 always in position 2. In this way, at least one input electrode is always used as a measuring electrode.

The fluids used to saturate the core and three-dimensional reservoir were an artificial brine containing 30.7 grams $\mathrm{NaCl}$ per liter of water with a resistivity of $0.215 \mathrm{ohm}$ meters and a $31.9^{\circ}$ API crude oil obtained from the Bartlesville Sandstone at a depth of 664 to 677 feet in Nowata County, Oklahoma. The only treatment of the oil was centrifugation to remove bottom sludge and water.

Core Tests (Two-Dimensional System With One-Dimensional Path)

A 76-cm-long by 3.8-cm-diameter core was obtained from an outcrop of the Cottage Grove Sandstone about 2 miles north of Dewey, Okla. This formation is a very uniform sandstone having a porosity of about 26 percent.

The core was equipped with electrodes by painting a band of silver print conductive paint around the core $15.2 \mathrm{~cm}$ from each end (figure 3). A bare end of an insulated lead was inserted in the silver print with the other end on the core end piece. The end pieces have platinum screens and leads for the end electrodes which are isolated from the silver band electrodes by plexiglass end pieces and a rubber sleeve. 


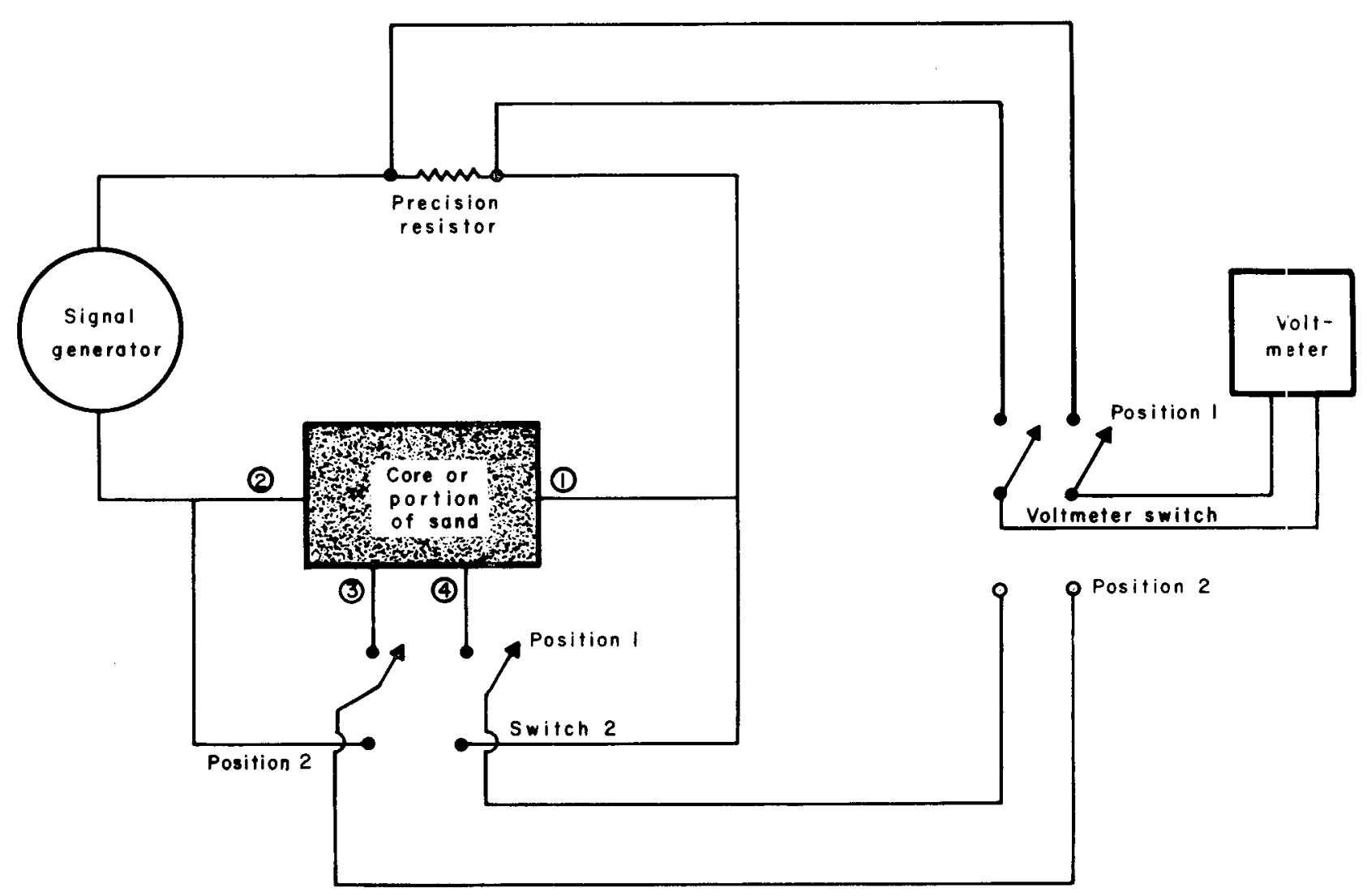

FIGURE 2. - Signal input and measurement for ac or dc measurements of the core or the model reservoir. Numbered circles indicate electrodes.

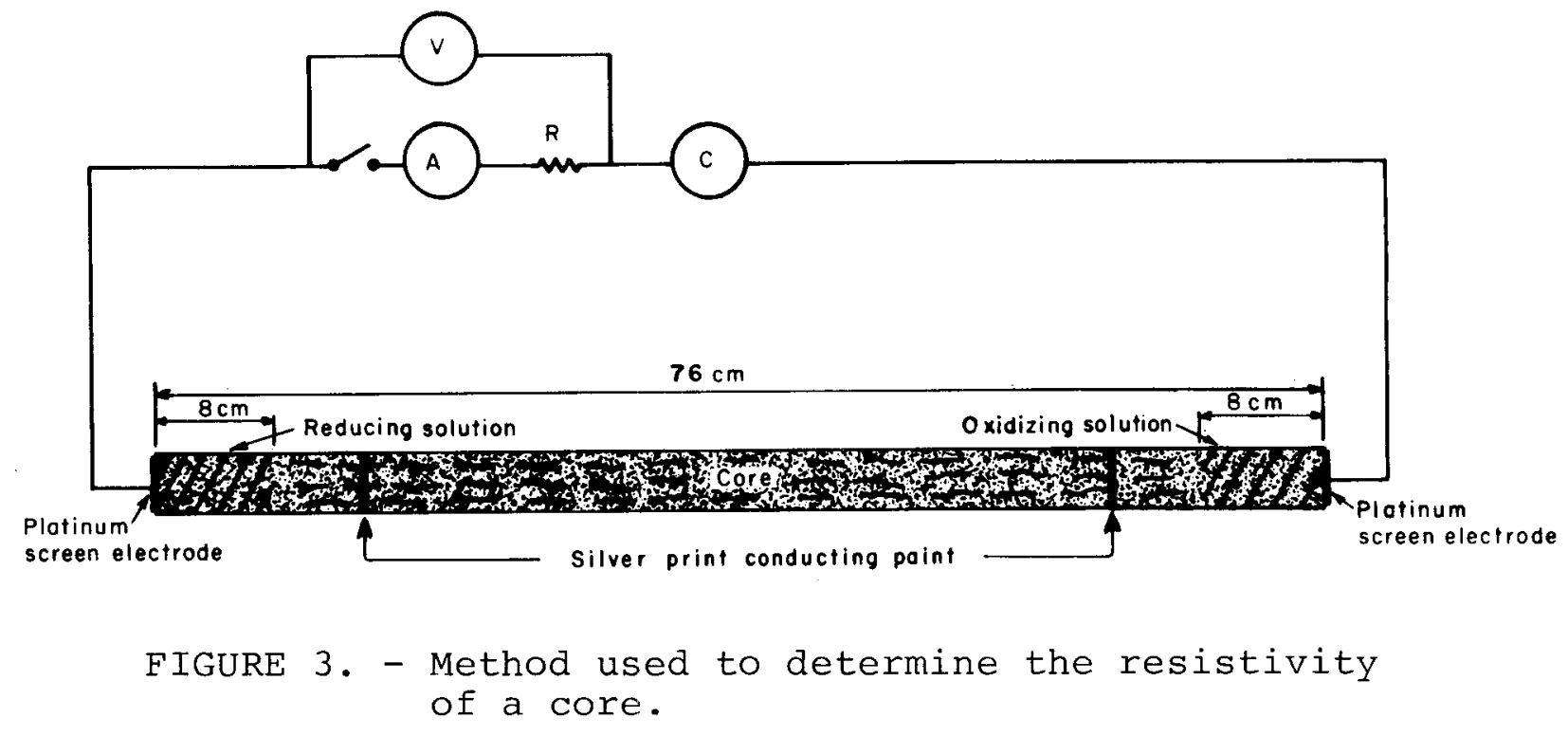


The core was dried and weighed (1,604.0 grams). The core was saturated with $227 \mathrm{ml}$ of brine and assembled with end pieces, wrapped with Saran wrap, and inserted in a Hassler-type holder (12). Water was pumped into the annulus between the rubber tube and the plexiglass outer tube to maintain a confining pressure of 50 psi.

Five pore volumes of brine were pumped through the core to ensure 100 percent brine saturation. The resistivity was measured using the four-electrode method (26) with $R_{0}=0.425 \mathrm{ohm}$ meter.

Oil was pumped into the core, keeping a careful material balance, until the core was at residual water saturation. Brine was pumped through the core stopping periodically to obtain 2- and 4-electrode resistivity measurements until residual oil saturation was reached. as follows:

The volume of all displaced fluids was measured and recorded

$\begin{array}{lll}\text { Volume of brine initially in core, } \mathrm{ml} & 227.00 \\ \text { Volume of brine displaced by oil, ml } & 128.5 \\ \text { Volume of brine remaining in core, } \mathrm{ml} & 98.5\end{array}$

Initial volume of oil in the core is equal to the volume of brine that was displaced by the oil (128.5 ml).

Initial volume of oil in core, $\mathrm{ml}$ 128.5 Volume of oil displaced by brine, ml $\frac{57.1}{71.4}$

Volume of oil remaining in core, $\mathrm{ml}$

A reducing solution was injected into one end of the core, and an oxidizing solution was placed in the other end. This was accomplished in one case by pumping $50 \mathrm{ml}$ of 0.5 molar ferrous chloride into one end and $25 \mathrm{ml}$ of 0.5 molar ferric chloride into the other end of the core sample. Thus, $25 \mathrm{ml}$ of each solution remained in the core. No additional oil was removed from the core during injection of these solutions.

Platinum screen electrodes, in contact with the two ends of the core, were connected to a commutator, voltmeter, ammeter, and $51,000 \mathrm{ohm}$ resistor, as shown in figure 3. The resistivity of the core containing the residual oil saturation was determined using the electric current that was generated by the reducing and oxidizing solutions. 
When the measurements were complete, 10 pore volumes of brine were pumped through the core to remove the oxidizing and reducing solutions, and the core was charged once more with $25 \mathrm{ml}$ of 0.5 molar solutions of cuprous and cupric chloride. Resistivity measurements were taken.

The copper solutions were removed from the core, and a third set of solutions was introduced by injecting $25 \mathrm{ml}$ samples each of a 0.05 molar solution of mercurous chloride in hydrochloric acid and a 0.3 molar solution of mercuric chloride from which resistivity measurements were obtained.

\section{Single Layer Three-Dimensional Model Reservoir} (Two-Dimensional Path)

A simple model was prepared by removing the large particles from building sand by topping it through a No. 14 sieve. A $6-\mathrm{cm}$ layer of the sand was added to a wooden box which was constructed $127 \mathrm{~cm}$ square and $40 \mathrm{~cm}$ high with the joints sealed with epoxy resin and the interior painted with a nonconducting marine paint.

Cylindrical copper electrodes, $3-\mathrm{cm}$ long with a diameter of $0.635 \mathrm{~cm}$, with insulated leads soldered at one end were inserted at the corners and center of a $40-\mathrm{cm}$ square grid in the center of the 127-cm square box. Two electrodes were imbedded in the grid halfway between the center and each of two adjacent corner electrodes. The seven electrodes were inserted vertically with the top $1.5 \mathrm{~cm}$ below the surface of the sand.

Fourteen liters of oil was mixed with the sand to make the sand oil-wet and to ensure a relatively uniform saturation. Brine was added making the volumetrically measured brine saturation for the entire reservoir 56 percent of pore volume.

Measurements were obtained with every possible combination of input and measuring electrodes. However, measured voltages were very small and showed much scatter for the four-electrode method (figure 2). As a result, only two- and three-electrode measurements were obtained as mentioned earlier. Both $20 \mathrm{~Hz}$ ac and dc inputs were used to measure the voltage in the reservoir. Calculations were made with the Poisson equation (Computer Program). 
Multiple Layer Three-Dimensional Model Reservoir (Two-Dimensional Path)

Wells which also served as electrodes were constructed by capping five $75-\mathrm{cm}$ lengths of $0.64-\mathrm{cm}$-diameter stainless steel (SS) tubing at one end. These capped tubes were placed in 1.91$\mathrm{cm}$-diameter tygon tubing and held in a vertical position. The annular space between the ss tubing and the tygon tubing was filled with concrete.

After the concrete hardened ( 3 days), a diamond saw was used to cut slots through the cement and into the ss tubing to act as perforations. The cuts were made over a $6-\mathrm{cm}$ portion of the tubing to coincide with the center of the sand zone. Four cuts were made in a radial fashion. The tygon tubing was removed, and an 8-cm-long piece of 50-50 mesh SS screen extending $1 \mathrm{~cm}$ past the slots at both ends was used to prevent sand intrusion. The screen was silver soldered at spots along the seam.

Shale tailings were obtained from drilling sites in Nowata county and immersed in a tank of water to form a mud shale. A $17-\mathrm{cm}$ layer of the mud shale was placed in the empty 127-cm box, and the wells were set in position in the shale forming a fivespot with the outer wells forming a l-meter square.

Building sand, which had been topped through a No. 14 sieve, was added to form a $10-\mathrm{cm}$ layer as the middle formation in the box. Oil (26.6 liters) and brine $(26.6$ liters) were poured simultaneously onto the sand giving a water saturation of 0.50. The measured porosity of the packed sand was 33 percent. A 9-cm layer of shale was added as the top formation in the miniature model reservoir.

Resistivity of the sand when 100 percent saturated with brine $\left(R_{0}\right)$ was determined using a 1.87-cm-diameter, sand-packed tube fitted with end electrodes. The two-electrode ac method (26) was used to determine an $R_{\text {o }}$ of 0.275 ohm meter.

Measurements of voltage and current for each set of wells were made with ac input. Values for $S_{w}$ were calculated using Poisson's equation.

The potential was checked between the wells with no impressed emf to determine the possibility of spontaneous potentials resulting from the difference in ion concentration at the sandshale interfaces. Voltages on the order of $0.1 \mathrm{v}$ were measured. The electrodes were shorted every night to discharge these as much as possible. 
One hundred milliliters of 0.5 molar ferric chloride was pumped into one well, and $100 \mathrm{ml}$ of 0.5 molar ferrous chloride was pumped into another well. Resistivity was measured using the emf from the oxidizing and reducing solutions.

Brine was pumped into the three remaining wells while producing the wells where oxidizing or reducing solutions were located. Background voltages were again obtained. The ferrous and ferric chloride solutions were pumped into two other wells. Voltages and currents were again obtained for resistivity calculations.

These solutions were removed, and the other oxidizing and reducing solutions described in the core tests were used. Values for $\mathrm{S}_{\mathrm{W}}$ were calculated for all the tests using Poisson's equa-tion.

\section{RESULTS AND DISCUSSION}

\section{Core Tests (Two-Dimensional System With One-Dimensional Path)}

Archie proposed a value of 2 for the constant, $n$, in equation (1) after correlations of experimental data on resistivity measurements published by several authors $(15,17,19,34)$. The value of $\mathrm{n}$ for the results of the two- and four-electrode resistivity measurements is 1.95 (figure 4). These results were obtained at various water saturations while displacing oil from the core with a brine solution and using impressed ac current to obtain the resistivity measurements.

Measurements and calculations for the resistivity data from the oxidizing and reducing solutions are given in table 1.

TABLE 1. - Results of resistivity measurements using oxidizing and reducing solutions.

\begin{tabular}{|c|c|c|c|c|c|c|c|}
\hline Solutions & $\begin{array}{c}R_{t^{\prime}} \\
\mathrm{ohm} \text { meter }\end{array}$ & $\begin{array}{l}\text { Sor, } \\
\text { Figure }\end{array}$ & 4 & $\begin{array}{c}\mathrm{S}_{\text {Or }} \\
\mathrm{m} \mathbf{1}\end{array}$ & $\begin{array}{c}\text { Sor' ml } \\
\text { volumetric }\end{array}$ & $\begin{array}{c}\text { Relative } \\
\text { error }\end{array}$ & $\mathrm{n}$ \\
\hline $\mathrm{Fe}^{++} / \mathrm{Fe}^{+++}$ & 0.89 & 32.0 & & 72.6 & 71.4 & 0.0168 & 2.0 \\
\hline $\mathrm{Cu}^{+} / \mathrm{Cu}^{++}$ & 1.064 & 37.0 & & 84.0 & 71.4 & 0.01765 & 2.4 \\
\hline $\mathrm{Hg}^{+} / \mathrm{Hg}^{++}$ & 1.018 & 35.0 & & 79.4 & 71.4 & 0.1120 & 2.3 \\
\hline
\end{tabular}

$$
\text { Relative error }=\frac{S_{\text {or-volumetric }} S_{\text {or }}}{\text { volumetric } S_{\text {or }}}
$$




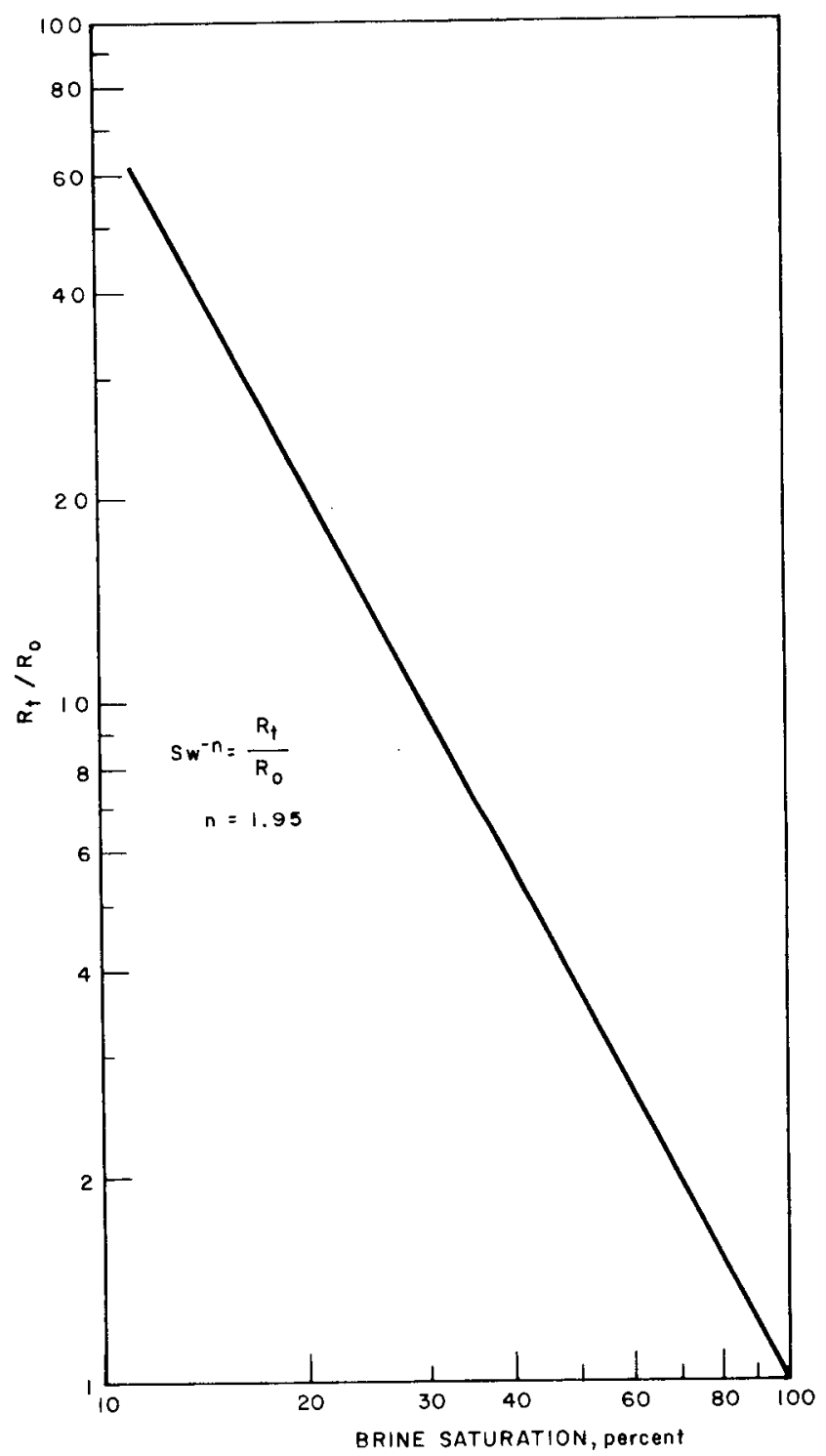

$\begin{aligned} \text { FIGURE 4. - } & \text { Resistivity as a function of brine } \\ & \text { saturation determined using a 76-cm- } \\ & \text { long by } 3.8-\mathrm{cm} \text {-diameter core. }\end{aligned}$

The average of the values of $n$ obtained from the oxidizing and reducing solutions is 2.2. Thus the experimental data from both ac input and oxidizing and reducing solutions are in close agreement with Archie's empirical correlations which are used extensively for electric logging calculations. 
Single Layer Three-Dimensional Model Reservoir (Two-Dimensional Path)

A simple reservoir with only one layer and impressed emf instead of the oxidizing and reducing solutions was used to develop experimental procedures, apparatus, and mathematics, and for experience.

Part of the experience gained involved determining electrode effective area for the finite difference modeling. Adams ( 1 ) suggests that this area may be considerably different from the electrode geometric area. However, our computer model gave very good results using the actual geometric area of one electrode, or since the electrodes were identical and geometrically symmetrical and parallel, one-half the geometric area of two electrodes multiplied by porosity and water saturation.

Calculations of the water saturations by the solution of Poisson's equation indicate an average saturation of 49.4 percent for $20 \mathrm{~Hz}$ square wave dc input and 44.0 percent for the $20 \mathrm{~Hz}$ ac input compared to a volumetric balance of 56.0 percent. Table 2 gives the saturation distribution between wells, and figure 5 is a saturation profile for the calculated water saturations for the solutions of Poisson's equation. The saturation profile indicates higher water saturations toward electrodes $W-1, W-2$, and $W-4$ and lower values near the center and toward electrode $W-$ 3 .

Figure 6 is an isopotential map of the miniature reservoir calculated by the solution of Poisson's equation. The impressed dc input is at electrodes $W-1$ and $W-2$. These isopotential lines agree in shape with the isopotential lines presented in Van Nostrand (27).

\section{Multiple-Layer, Three-Dimensional Model Reservoir} (Two-Dimensional Path)

After experience in the modeling procedure had been gained using the simple reservoir, a three-layer model was constructed. Data were taken using impressed emf; then oxidizing and reducing solutions were introduced into the wells to generate an emf, but the results were inconclusive. The measured voltages, with no oxidizing or reducing solutions and no impressed emf, were on the order of 0.1 volt. The measured voltages with the oxidizing and reducing solutions did not differ significantly from the values recorded without the solutions present. Apparently, the solutions migrated along the bottom shale layer and came in contact with each other causing anomalous measurements. Only the impressed emf's were used in the calculations, and, because of time limitations, no additional experiments with oxidizing and reducing solutions were run. 
TABLE 2. - Water saturation between electrodes in the single layer three-dimensional model reservoir calculated by the finite difference solution of Poisson's equation.

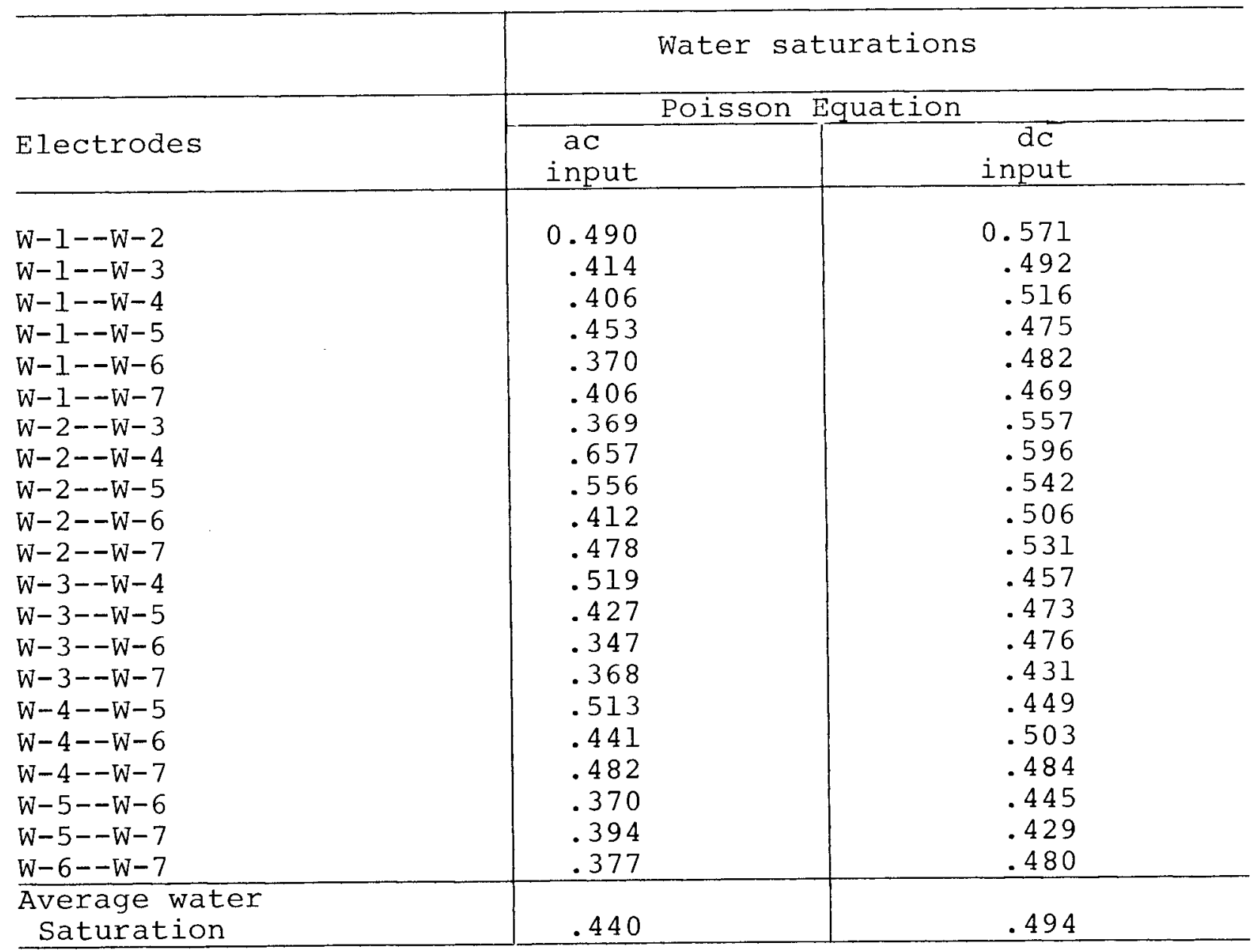




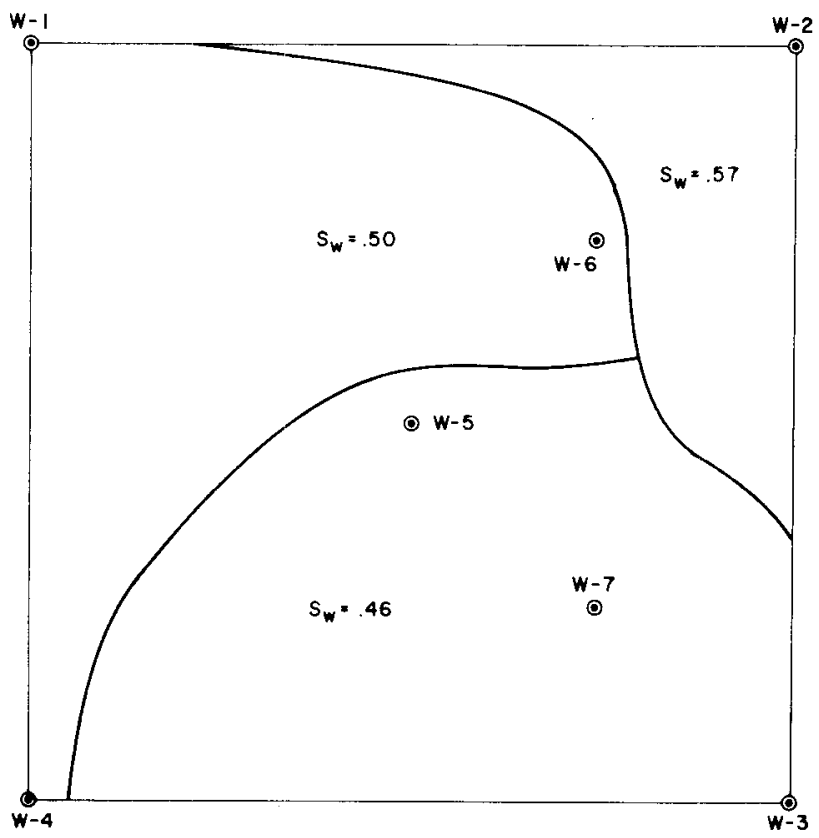

FIGURE 5. - Brine saturation distribution calculated from the Poisson equation for a singlelayer, three-dimensional model reservoir.

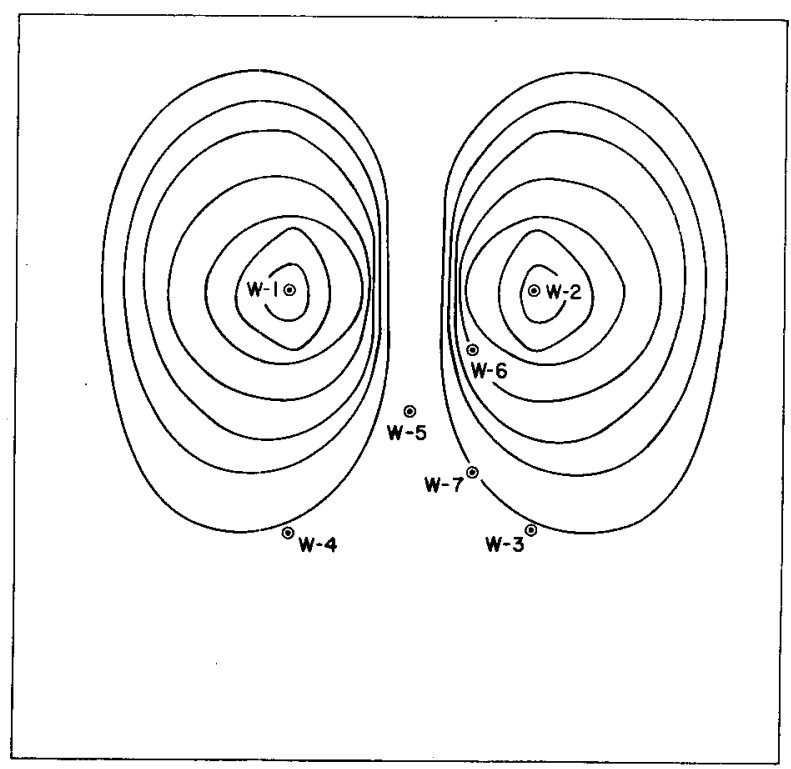

FIGURE 6. - Isopotential lines calculated from the solution of Poisson's equation with input at wells $\mathrm{W}-1$ and $\mathrm{W}-2$ in a single layer-model. 


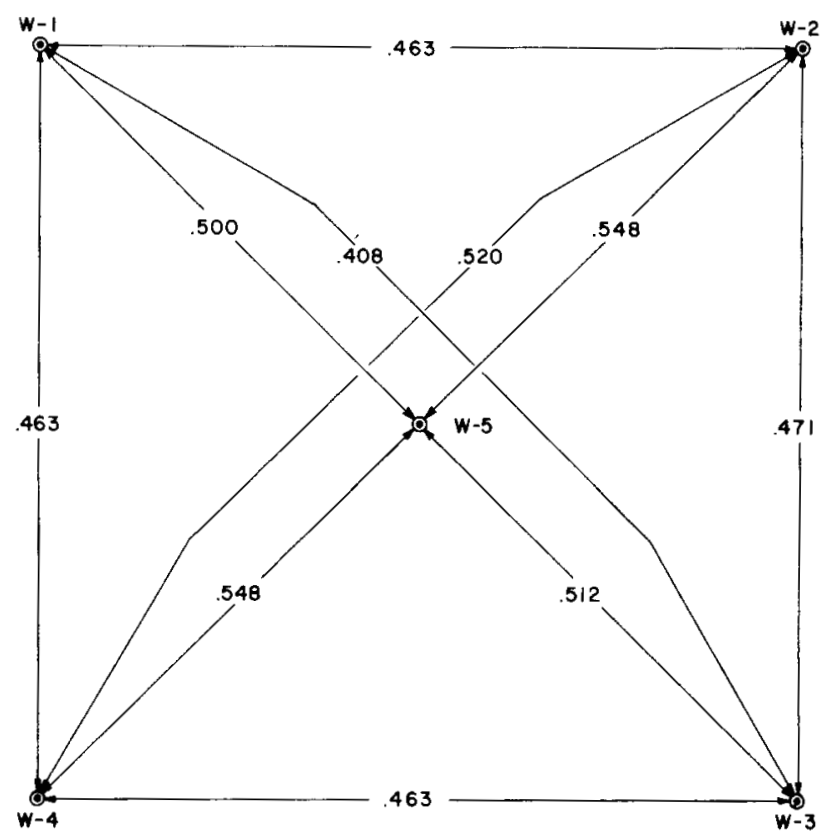

FIGURE 7. - Brine distribution calculated between wells in a multilayered, three-dimensional model reservoir using Poisson's equation.

With the impressed emf, the average water saturation calculated from the Poisson equation was 49.1 percent compared to 50.0 percent by material balance. Figure 7 shows the saturation distribution between wells. The water saturation is higher toward the center and lower near the boundaries of the box.

\section{CONCLUSIONS}

This work was an attempt to develop a novel approach for accurate determination of fluid saturations throughout the formation. It has proved successful in a laboratory model. More work should be done in a field situation by persons familiar with electrode design and configurations. Electrode design and methods of introducing an electric current between wells in a formation remain to be worked out, but dc currents have been used over large distances in mineral prospecting and in ultralong-spaced logging techniques.

The two-dimensional system (core) presents no problems in determining oil and brine saturations from resistivity data. The low emf from the oxidizing and reducing solutions provides adequate current for determining resistivities in these systems, and Archie's relationship and value for $n$ allow accurate calculation of water saturation from the resistivity data. 
Poisson's equation gave excellent results. This method of computer modeling is directly applicable to field situations since the computer program can be modified to include known heterogeneities. 


\section{NOMENCLATURE}

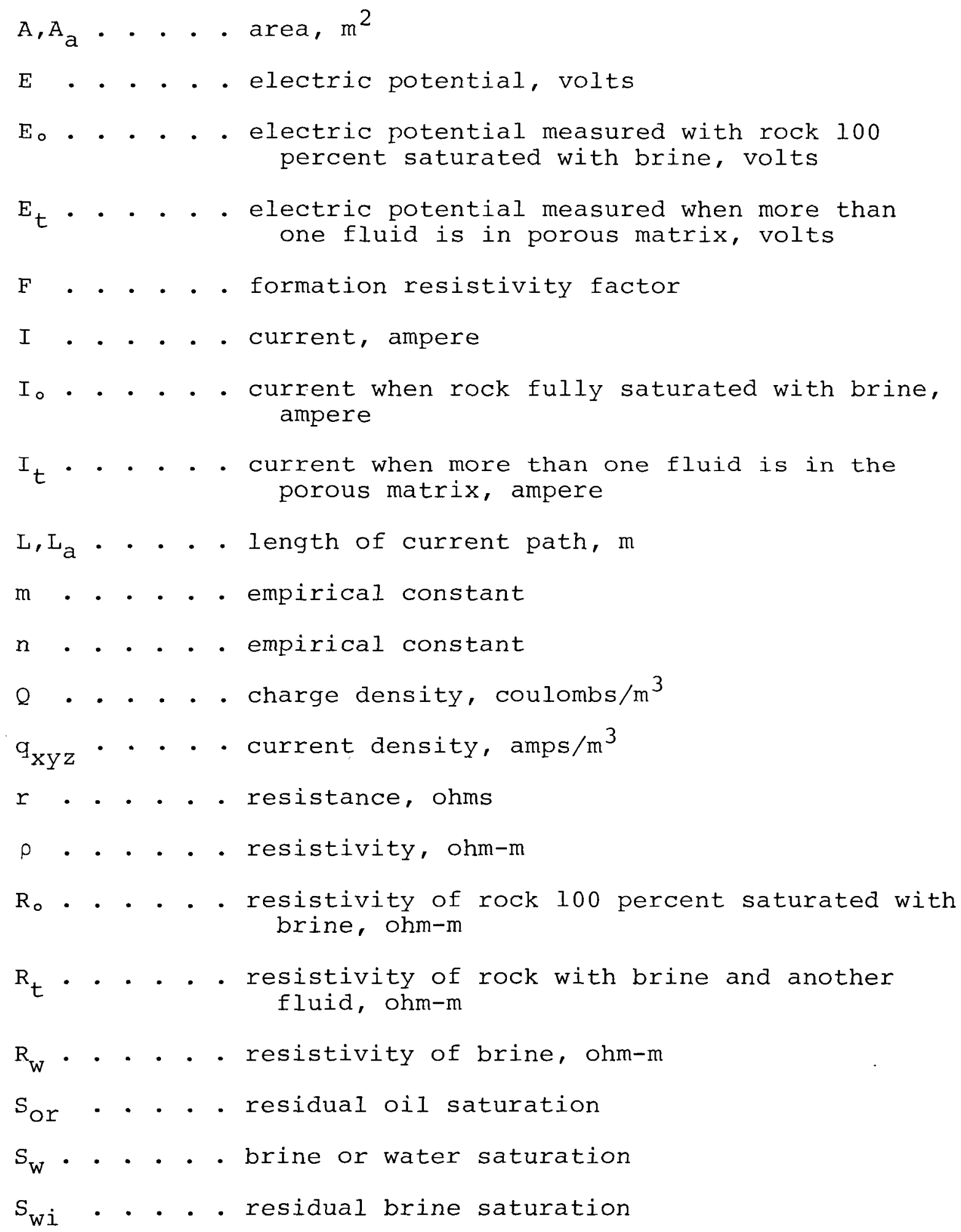




\section{NOMENCLATURE-Continued}

$$
\begin{aligned}
& \text { V . . . . electric potential, volts } \\
& \text { Z . . . formation thickness, m } \\
& \varnothing \cdot . \cdot \text {. } . \text { porosity }
\end{aligned}
$$




\section{REFERENCES}

1. Adams, R. N. Electrochemistry at Solid Electrodes. Marcel Dekker, Inc., New York, N.Y., 1969, pp. 43-66.

2. Amyx, J. W., D. M. Bass, Jr., and R. L. Whiting. Petroleum Reservoir Engineering. McGraw-Hill Book Co., Inc., New York, 1960, pp. 110-129.

3. Archie, G. E. The Electrical Resistivity Log as an Aid in Determining some Reservoir Characteristics. Trans. AIME, v. 146, 1942, pp. 54-62.

4. Arps, J. J. The Effect of Temperature on the Density and Electrical Resistivity of Sodium Chloride Solutions. Trans. AIME, v. 198, 1953, pp. 327-330.

5. Breitenbach, E. A., D. H. Thurnau, and H. K. van Poolen. Solution of the Immiscible Fluid Flow Simulation Equations. J. Soc. Petrol Eng., v. 9, No. 2, June, 1969, pp. 155-169.

6. Carter, L. S. The Relationship Between Electrical Resistivity and Brine Saturation. Petrol Eng., v. 23, No. 12, November 1951, pp. b60, b63-b64, b66, b68.

7. Crichlow, H. B. Modern Reservoir Engineering. PrenticeHall, Inc., Englewood Cliffs, N.J., 1977, pp. 141-146.

8. Dunlap, H. F., H. L. Bilhartz, E. Shuler, and C. R. Bailey. The Relation Between Electrical Resistivity and Brine Saturation in Reservoir Rocks. Trans. AIME, V. 186, 1949, pp. 259-260.

9. Fertl, W. H., and E. B. Reynolds. Determination of Residual Oil in a Formation. U.S. Pat. 3,878,890, April 22, 1975, $7 \mathrm{pp}$.

10. Forsythe, G. E. and W. R. Wasow. Finite-Difference Methods for Partial Differential Equations. John Wiley and Sons, New York, 1960 .

11. Guyod, H. Fundamental Data for the Interpretation of Electric Logs. Oil Weekly, v. 115, No. 38, Oct. 30, 1944 , pp.

12. Hassler, G. L. Method and Apparatus for Permeability Measurements. U.S. Pat. 2,345,935, April 4, 1944, 6 pp. 
13. Holmes, C.R. Some Factors Related to the Measurement of the Electrical Properties of Porous Sandstones. Producer's Monthly, v. 19, No. 1, November 1954, pp. 21-27.

14. Howell, B. F., Jr. Electrical Conduction in FluidSaturated Rocks. World Oil, v. 136, No. 2, Feb. 1, 1953, pp. 113-114, 1.16.

15. Jakosky, J.J., and R. H. Hopper. The Effect of Moisture on the Direct Current Resistivities of Oil Sands and Rocks. Geophys., v. 2, 1937, pp. 33-53.

16. Koerperich, E. A. Applications of Waxman-Smits and Archie Equations for Determination of oil Saturation in Shaly Sand Reservoirs. Pres. at 49 th Ann. Fall Meeting, Soc. Petrol. Eng., AIME, Houston, Tex., Oct. 6-9, 1974. SPE Paper 5038, 12 pp.

17. Leverett, M.C. Flow of Oil-water Mixtures Through Unconsolidated Sands. Trans. AIME, v. 132, 1939, pp. 149-172.

18. Martin, M. and J. L. Dumanoir. Determining True Resistivity. World Oil, v. 143, No. 1, July 1956, pp. 95-98, 100, 102, 105,108 .

19. Martin, M., G. H. Murray, and W. J. Gillingham. Determination of the Potential Productivity of Oil-bearing Formations by Resistivity Measurements. Geophys., v. 3, 1938, pp. 258-272.

20. Mungan, N. A Theoretical and Experimental Coning Study. J. Soc. Petrol. Eng., V. 15, No. 3, June 1975, pp. $247-254$.

21. Owen, J. E. The Resistivity of a Fluid-Filled Porous Body. Trans. AIME, v. 195, 1952, pp. 169-174.

22. Patnode, H. W. and M. R. J. Wyllie. The Presence of Conductive solids in Reservoir Rocks as a Factor in Electric Log Interpretation.' Trans. AIME, V. 189, 1950, pp. 47-52.

23. Perkins, Jr., F. M., H. R. Brannon, Jr., and W. O. Winsauer. Interrelation of Resistivity and Potential of Shaly

Reservoir Rock. Trans. AIME, v. 201, 1954, pp. 176-181.

24. Ral1, C. G. and J. Wright. Analyses of Formation Brines in Kansas. BuMines RI 4974, May 1953, 40 pp. 
25. Runge, R. J., A. E. Worthington and D. R. Lucas. ULSEL Logging Can Find Hidden Oil Reserves. World Oil, V. 170, No. 5, April 1970, pp. 67-71.

26. Rust, C. F. Electrical Resistivity Measurements on Reservoir Rock Samples by the Two-Electrode and Four-Electrode Methods. Trans. AIME, v. 195, 1952, pp. 217-224.

27. Van Nostrand, R. G. and K. L. Cook. Interpretation of Resistivity Data. Geological Survey Professional paper 499, 1966.

28. Vinal, G. W. Storage Batteries. John Wiley and Son, Inc., New York, 3rd ed., 1949, pp. 163-172.

29. Watts, J. W. An Iterative Matrix Solution Suitable for Anisotropic Problems. Soc. Pet. Eng. Reprint Series No. 11, NUMERICAL SIMULATION, Soc. Petrol. Eng., Dallas, Texas, 1973, pp. 119-123.

30. Waxman, M. H., and L. J. M. Smits. Electical Conductivities in Oil-Bearing Shaly Sands. J. Soc. Petrol. Eng., v. 8, June 1968, pp. 107-122.

31. Waxman, M. H., and E. C. Thomas. Electrical Conductivities in Shaly Sands-1. The Relation Between Hydrocarbon Saturation and Resistivity Index; 11. The Temperature Coefficient of Electrical Conductivity. J. Petrol. Tech., v. 26, February 1974, pp. 213-225.

32. Williams, M. Estimation of Interstitial Water from the Electric Log. Trans. AIME, v. 189, 1950, pp. 295-308.

33. Witte, L. de. Relations Between Resistivities and Fluid Contents of Porous Rocks. Oil and Gas J., V. 49, No. 16, Aug. 24, 1950, pp. 120-122, 124, 126, 128-132.

34. Wyckoff, R. D., and H. G. Botset. Flow of Gas Liquid Mixtures Through Sands. Phys., v. 7, 1936, pp. 325-345.

35. Wyllie, M. R. J. and W. D. Rose. Some Theoretical Considerations Related to the Quantitative Evaluation of the Physical Characteristics of Reservoir Rock from Electrical Log Data. Trans. AIME, v. 189, 1950, pp. 105-118.

36. Wyllie, M. R. J., and P. F. Southwick. An Experimental Investigation of the S.P. and Resistivity Phenomena in Dirty Sands. J. Petrol. Tech., v. 6, No. 2, February 1954, pp. 44-57. 


\section{APPENDIX}

Combining equations (5) $\underline{\text { I/ }}$ and (6) yields:

$-\left[\frac{\partial}{\partial x}\left(z \frac{\partial v}{\partial x}\right)+\frac{\partial}{\partial y}\left(z \frac{\partial v}{\partial y}\right)\right]-P I / A \varnothing=0$

which is then discretisized as follows:

$$
\begin{aligned}
& \frac{1}{D x}\left[\frac{z_{i, j}}{D x}\left(v_{i+1, j}-v_{i, j}\right)-\frac{z_{i, j}}{D x}\left(v_{i, j}-v_{i-1, j}\right)\right]+\frac{1}{D y} \\
& {\left[\frac{z_{i, j}}{D y}\left(v_{i, j+1}-v_{i, j}\right)-\frac{z_{i, j}}{D y}\left(v_{i, j}-v_{i, j-1}\right)\right]+} \\
& \rho I / A \varnothing=0
\end{aligned}
$$

If a grid with equal spacing in the $X$ and $Y$ directions is used and the following terms are defined, equation $(A-2)$ is reduced to:

$$
\begin{aligned}
D x= & D Y, \quad P I=P J=M I=M J=z_{i j} /(D x)^{2}, \text { and } \alpha=(P I+M I+P J+M J) \\
& \alpha \cdot V_{i, j}+P I \cdot V_{i+1, j}+M I \cdot V_{i-1, j}+P J \cdot V_{i, j+1}+M J \cdot V_{i, j-I}+ \\
& P I / A \emptyset=0
\end{aligned}
$$

In cases where the reservoir thickness, $z$, varies within the zone under investigation, $\mathrm{z}_{i j}$ can be enterea as input data at each node of the finite grid network. The reservoir used in the experiments described in this report had a constant thickness
In the program, equation (A-3) was multiplied through by (DX) $/ Z$ and the coefficients PI, MI, PJ, and MJ were equated to 1.0 and retained in the equation to facilitate modification if variable thickness or unequal spacing was used later, consequently:

$$
\begin{aligned}
P I=M I=P J=M J & =1.0 \\
\alpha & =-4.0
\end{aligned}
$$

If Equation numbers without the A-prefix refer to equations occuring in the main text. 


$$
\begin{aligned}
& \alpha \cdot V_{i, j}+P I \cdot V_{i+1, j}+M I \cdot V_{i-1, j}+P J \cdot V_{i, j+1}+M J \cdot V_{i, j-1}+ \\
& \quad \rho I(D x)^{2} / \varnothing Z A=0
\end{aligned}
$$

Referring to figure $A-1, V_{j j}=0$ for all boundary nodes, and the objective of the model is to evaluate the potential function, $\mathrm{V}_{i j}$, for all elements within the null boundaries. With these conditions, the problem is solved by successive line overrelaxation (10) which is an implicit method by which a line of components of $\mathrm{V}^{\mathrm{n}}$, are defined simultaneously in such an interrelated manner thatiit is necessary to solve a linear sub-system of the whole set of components at once before a single one can be determined. That is, the equation is solved implicitly for each row, sweeping down the columns (figure $\mathrm{A}-1$ ) in a row-by-row fashion. The equation $(A-5)$ incorporates an iteration parameter, $W$, in the tridiagonal matrix call. The reader is referred to the literature for a detailed description of the successive line overrelaxation technique Eor solving matrices $(5,7,10,28)$. Figure $A-2$ illustrates the relationship between the known and unknown values that is used to transform equation $(A-4)$ to $(A-5)$. This equation is written for each point within the boundaries of figure A-1 to create the set of simultaneous algebraic equations that must be solved.

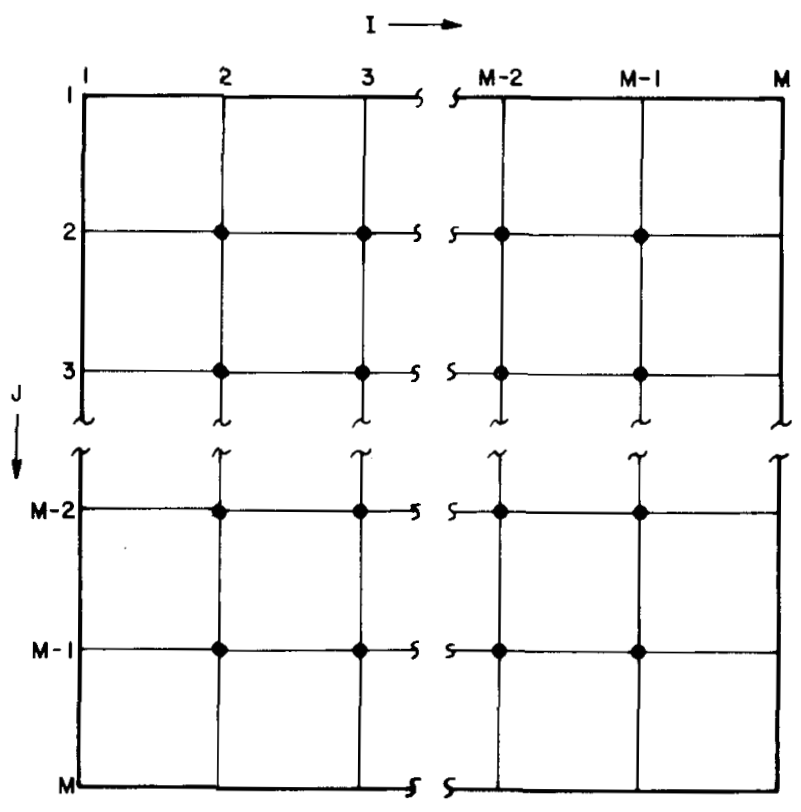

FIGURE A-1. - Finite difference ğrid. 


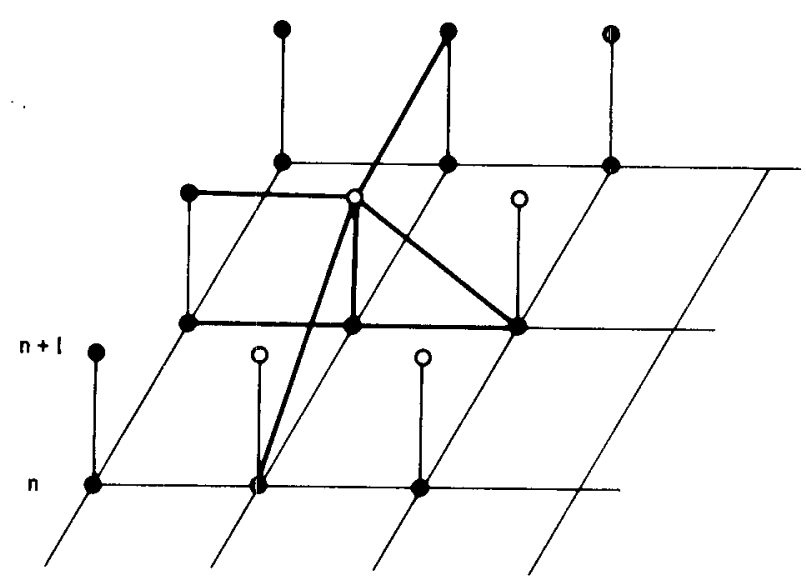

FIGURE A-2. - Relationship between the known (filled-in circles) and unknown (open circles) values in the grid.

$$
\begin{gathered}
{\left[M I \cdot V_{i-1, j}+P I \cdot V_{i+1, j}+\alpha V_{i, j}\right]^{n+1}=\left[( 1 - W ) \left(M I \cdot V_{i-1, j}+\right.\right.} \\
\left.\left.P I \cdot V_{i+1, j}+\alpha V_{i, j}\right)\right] n-W\left[M J \cdot V_{i, j-1} n+1+P J \cdot V_{i, j+I}+\right. \\
\left.\rho I(D x)^{2} / \varnothing Z A\right]=0
\end{gathered}
$$

Defining the last term: $\mathrm{ZAP}_{i j}=\rho \mathrm{I}(\mathrm{Dx})^{2} / \not \mathrm{ZA}$

$$
\begin{gathered}
P I \cdot V_{i+1, j}+\alpha V_{i, j}=(l-W) \quad\left[M I \cdot V_{i-1, j}+P I \cdot V_{i+1, j}+\alpha V_{i, j}\right]- \\
W\left[M J \cdot V_{i, j-1} n+1+P J \cdot v_{i, j+1}+Z A P_{i, j}\right]-M I \cdot V_{i-1, j}= \\
D_{2}-\cdots \substack{I=2, m-1 \\
j=2}_{(A-6)}
\end{gathered}
$$

Moving the known to the right-hand side and writing equation (A-6) for the nodes of row $J=2$, the generalized equation for any row and node emerges as equation $(A-7)$ :

$$
M I \cdot V_{i-1, j}+P I \cdot V_{i+1, j}+\alpha V_{i, j}=(1-W)\left[M I \cdot V_{i-1, j}+P I \cdot V_{i+1, j}+\right.
$$




$$
\begin{gathered}
\left.\alpha v_{i, j}\right]-W\left[M J \cdot v_{i, j-1}{ }^{n+1}+P J \cdot v_{i, j+1}+Z A P_{i, j}\right]= \\
D_{n}---\quad \underset{\substack{I=3, m-2 \\
j=2}}{ }
\end{gathered}
$$

There is an equation of the form of equation ( $A-7$ ) for each column of the nodes shown in figure $A-1$, making a tridiagonal set which is solved by Gaussian elimination (subroutine TRIDAG). Figure $A-3$ is a listing of the main program and subroutine TRIDAG; statement number 159 is the expression of equation (A-7). Figure $A-4$ is a flow diagram of the program showing the main characteristics. 
FIGURE A-3. - Computer Program for calculation of voltages and water saturation in

a laboratory model.

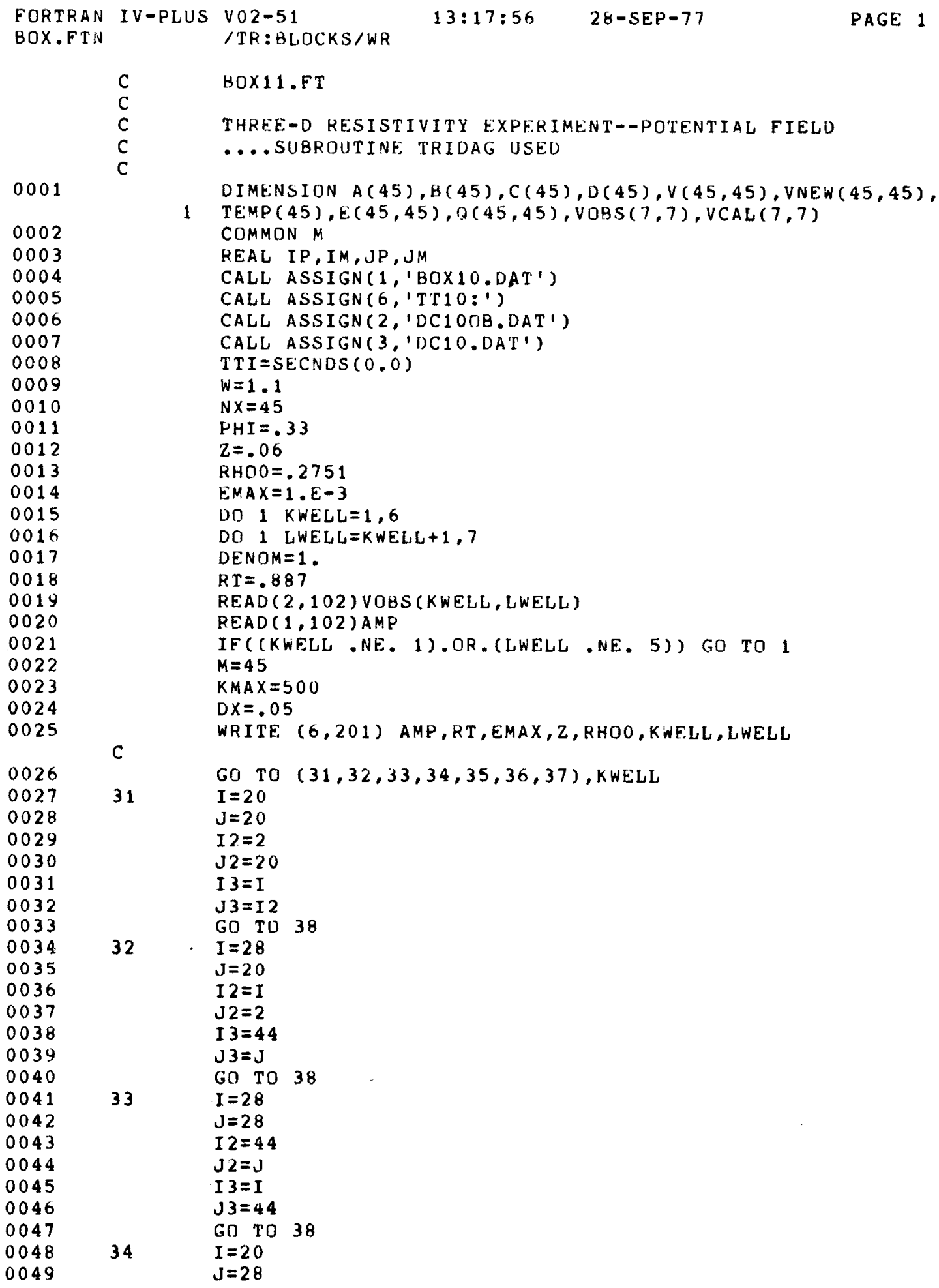


FIGURE A-3 (Cont.)

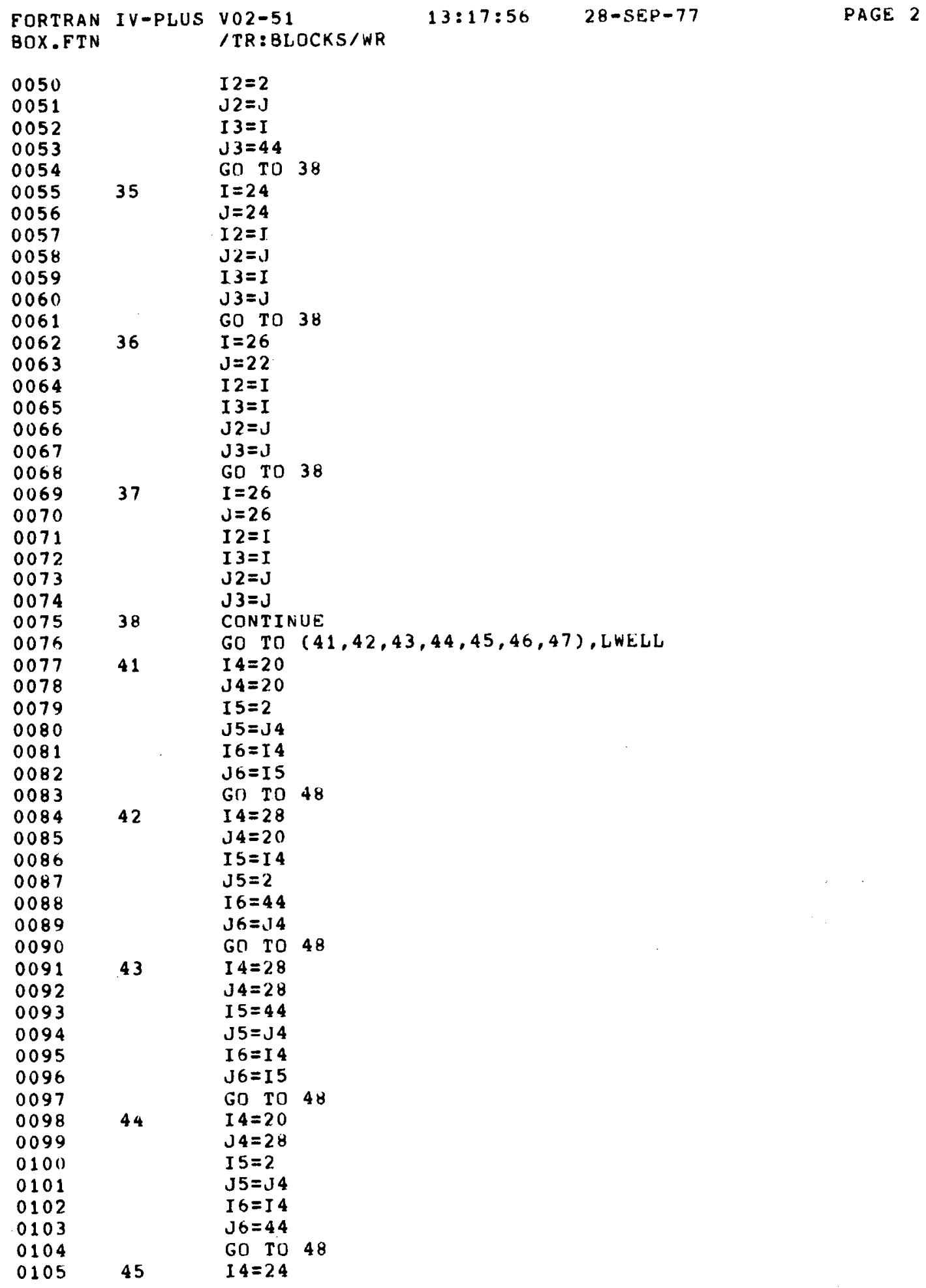


FIGURE A-3 (Cont.)

FORT'RAN IV-PLUS

BOX.FTN

V02-51

$13: 17: 56 \quad 28-S E P-77$

PAGE 3

0106

0107

0108

0109

0110

0111

0112

0113

0114

0115

0116

0117

0118

0119

0120

0121

0122

0123

0124

0125

0126

0127

0128

0129

0130

0131

0132

0133

0134

0135

0136

0137

0138

0139

0140

0141

0142

0143

0144

$47 \quad$ GO TO 48

$\mathrm{J} 4=24$

$I 5=I 4$

I $6=I 4$

$\mathrm{J} 5=\mathrm{J} 4$

$\mathrm{J} 6=\mathrm{J} 4$

$46 \quad I 4=26$

$\mathrm{J} 4=22$

$15=14$

$16=I 4$

$\mathrm{J} 5=\mathrm{J} 4$

$\mathrm{J} 6=\mathrm{J} 4$

$\begin{aligned} 47 \quad \mathrm{I} 4 & =26 \\ \mathrm{~J} 4 & =26\end{aligned}$

I $5=I 4$

$I 6=14$

$\mathrm{J} 5=\mathrm{J} 4$

$J 6=J 4$

48 CONTINUE

100 FORMAT (2I2)

WRITE $(6,210) I, J, I 4, J 4$

WRITE $(6,260) 12, \mathrm{~J} 2,13, \mathrm{~J} 3, \mathrm{I} 5, \mathrm{~J} 5, \mathrm{I} 6, \mathrm{~J} 6$

260 FORMAT(' IMAGE ELECTRODES ARE AT $(1, \mathrm{I} 2,1,1, \mathrm{I} 2,1),($,

$\left.551, I 2,1,1, I 2,1),(1, I 2,1,1, I 2,1) \&\left(1, I 2,1^{\prime}, 1, I 2,1\right),{ }^{\prime}\right)$

$S W=S O R T(R H O O / R T)$

DO 2 IK $=1, M$

DO $2 J K=1, M$

$\theta(I K, J K)=0$.

$V(I K, J K)=0$.

$2 \quad \operatorname{VNEW}(I K, J K)=0$.

AREA $=0.0006 * S W$

$Z A P=R T * A M P * D X * D X /(Z * P H I * S W)$

$Q(I, J)=Z A P / A R E A$

$O(I 2, J 2)=O(I, J)$

$Q(I 3, J 3)=Q(I, J)$

$Q(I 4, J 4)=-Q(I, J)$

$O(I 5, J 5)=Q(I 4, J 4)$

$Q(16, J 6)=O(14, J 4)$

210 FORMAT (' INPUT CURRENT IS BETWEEN COORDINATES',

$0145 \quad 3 \quad k=0$

$0146 \quad 4 \quad k=k+1$

$0147 \quad I O K=0$

0148

0149

0150

0151

0152

0153

0154

0155

0156

0157

C

ING $=0$

DO $8 \quad J K=2, M-1$

DO 6 IK $=2, M-1$

$I P=1$.

$I M=1$.

$J P=1$.

$J M=1$.

$A L=-I P-I M-J M-J P$

$A(I K)=I M$

$B(I K)=A L$ 
FIGURE A-3 (Cont.)

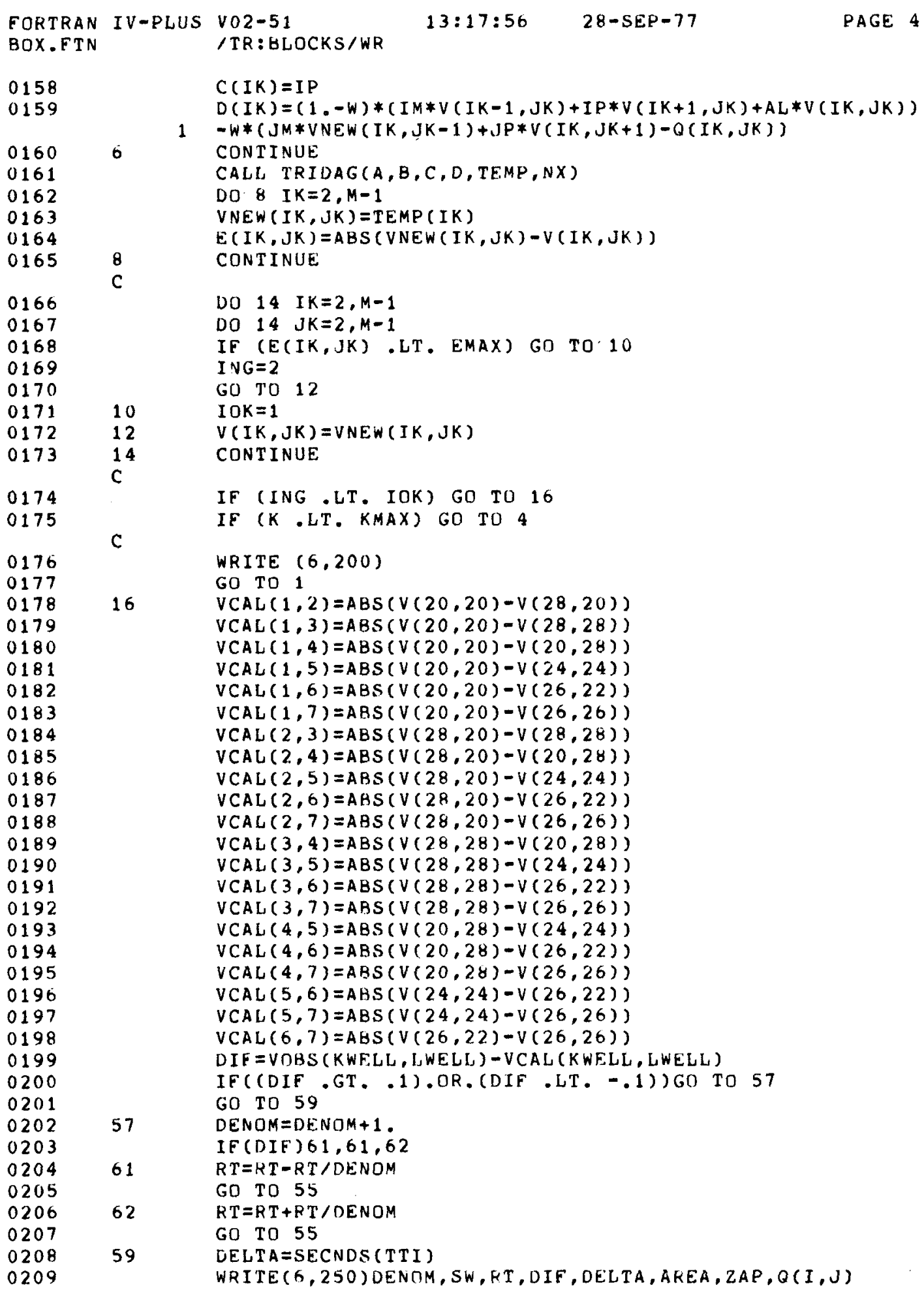


FIGURE A-3 (Cont.)

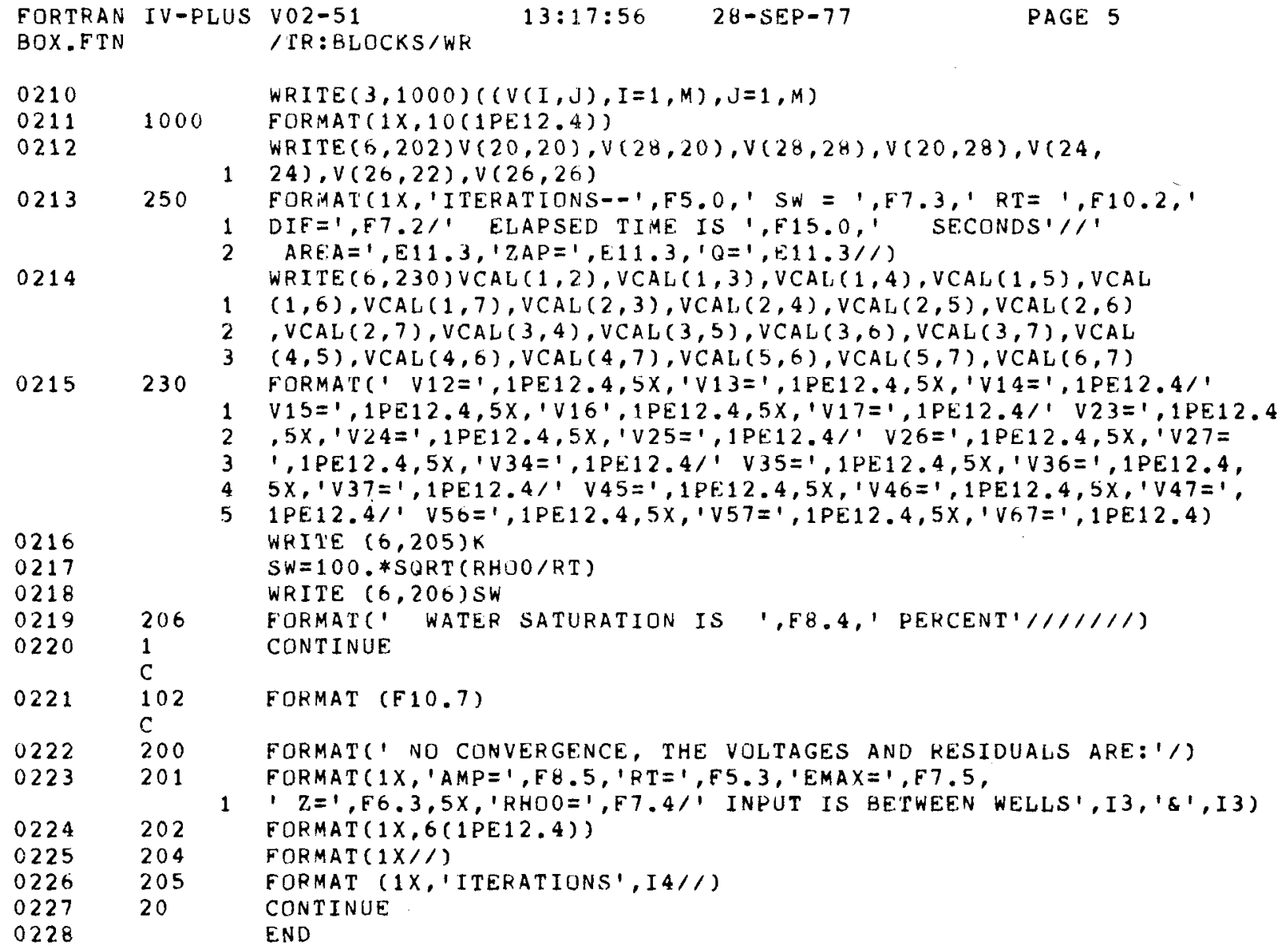

PAGE 1

0001

0002

0003

0004

0005

0006

0007

0008

0009

0010

0011

0012

0013

0014

0015

0016

0017

0018

SUBROUTINE TRIDAG $(A, B, C, D, V, N X)$

DIMENSION $A(N X), B(N X), C(N X), D(N X), V(N X), \operatorname{BETA}(101), \operatorname{GAMMA}(101)$

COMMON M

$L=M-1$

$I F=2$

BETA (IF ) $=B($ IF )

GAMMA (IF) $=D($ IF $) / B E T A($ IF )

IFP $1=I F+1$

DO 1 I $=I F P 1, L$

$\operatorname{BETA}(I)=B(I)-A(I) * C(I-1) / B E T A(I-1)$

1 GAMMA (I ) $=(D(I)-A(I) * G A M M A(I-1)) / B E T A(I)$

$V(L)=G A M M A(L)$

LAST $=\mathrm{L}-\mathrm{IF}$

DO $2 K=1$, LAST

$I=L-K$

$2 \quad V(I)=\operatorname{GAMMA}(I)-C(I) * V(I+1) / B E T A(I)$

RETURN

END 


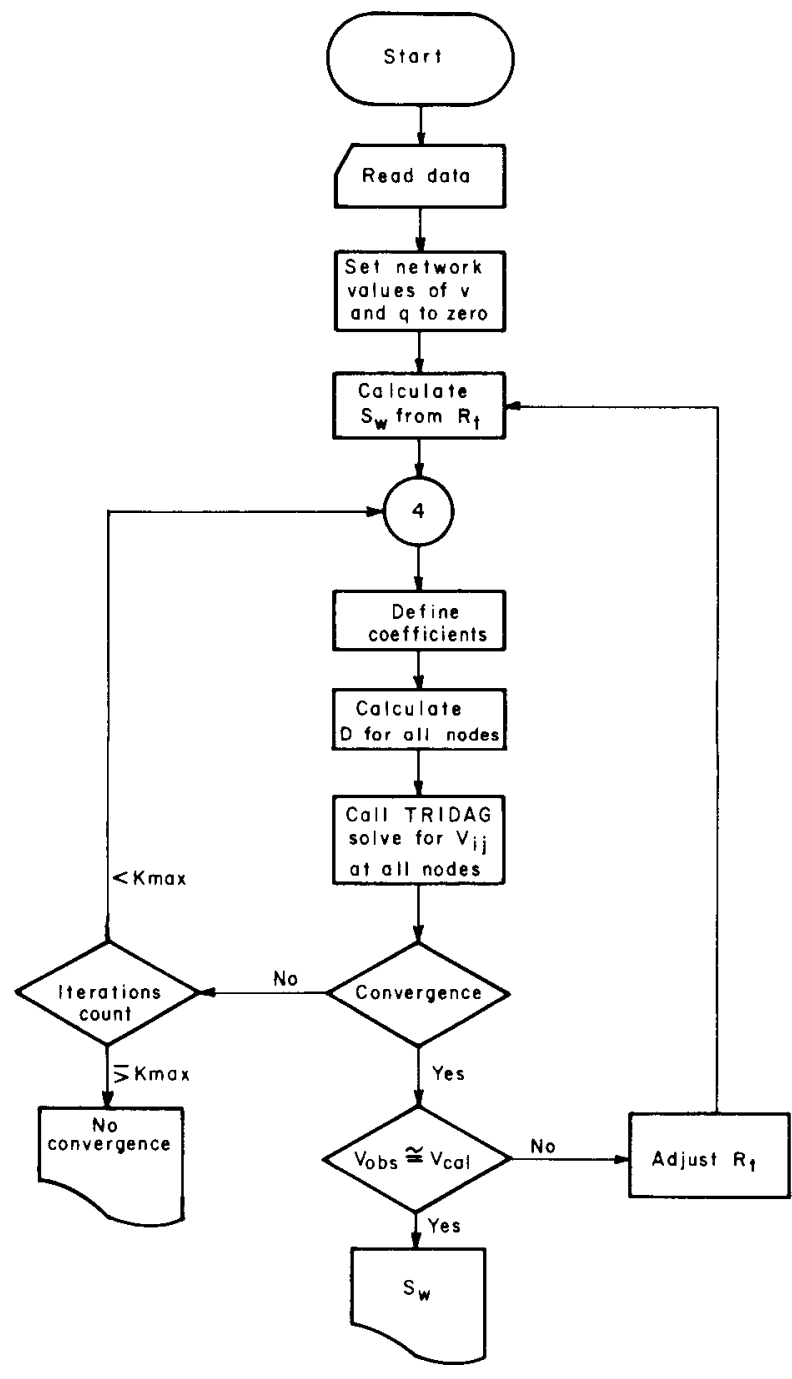

FIGURE A-4. - Flow diagram of the computer program showing the main characteristics. 